\title{
Adenosine Released by Astrocytes Contributes to Hypoxia-Induced Modulation of Synaptic Transmission
}

\author{
EDUARDO D. MARTÍN,${ }^{1}$ MIRIAM FERNÁNDEZ, ${ }^{1}$ GERTRUDIS PEREA, ${ }^{2}$ OLIVIER PASCUAL, ${ }^{3}$ \\ PHILIP G. HAYDON, ${ }^{3}$ ALFONSO ARAQUE, ${ }^{2 *}$ AND VALENTÍN CENA ${ }^{1}$ \\ ${ }^{1}$ Unidad Asociada Neurodeath, UCLM-CSIC, Departamento de Ciencias Médicas, Universidad de Castilla-La Mancha, \\ Albacete, Spain \\ ${ }^{2}$ Instituto Cajal, Consejo Superior de Investigaciones Científicas, Madrid, Spain \\ ${ }^{3}$ Department of Neuroscience, Conte Center for Integration at the Tripartite Synapse, University of Pennsylvania School \\ of Medicine, Philadelphia, Pennsylvania
}

KEY WORDS

ATP; presynaptic modulation; synaptic plasticity; astrocyte modulation

\begin{abstract}
Astrocytes play a critical role in brain homeostasis controlling the local environment in normal as well as in pathological conditions, such as during hypoxic/ischemic insult. Since astrocytes have recently been identified as a source for a wide variety of gliotransmitters that modulate synaptic activity, we investigated whether the hypoxia-induced excitatory synaptic depression might be mediated by adenosine release from astrocytes. We used electrophysiological and $\mathrm{Ca}^{2+}$ imaging techniques in hippocampal slices and transgenic mice, in which ATP released from astrocytes is specifically impaired, as well as chemiluminescent and fluorescence photometric $\mathrm{Ca}^{2+}$ techniques in purified cultured astrocytes. In hippocampal slices, hypoxia induced a transient depression of excitatory synaptic transmission mediated by activation of presynaptic A1 adenosine receptors. The glia-specific metabolic inhibitor fluorocitrate (FC) was as effective as the $\mathrm{A} 1$ adenosine receptor antagonist CPT in preventing the hypoxia-induced excitatory synaptic transmission reduction. Furthermore, FC abolished the extracellular adenosine concentration increase during hypoxia in astrocyte cultures. Several lines of evidence suggest that the increase of extracellular adenosine levels during hypoxia does not result from extracellular ATP or cAMP catabolism, and that astrocytes directly release adenosine in response to hypoxia. Adenosine release is negatively modulated by external or internal $\mathrm{Ca}^{2+}$ concentrations. Moreover, adenosine transport inhibitors did not modify the hypoxia-induced effects, suggesting that adenosine was not released by facilitated transport. We conclude that during hypoxia, astrocytes contribute to regulate the excitatory synaptic transmission through the release of adenosine, which acting on $\mathrm{A} 1$ adenosine receptors reduces presynaptic transmitter release. Therefore, adenosine release from astrocytes serves as a protective mechanism by down regulating the synaptic activity level during demanding conditions such as transient hypoxia. ๑2006 Wiley-Liss, Inc.
\end{abstract}

\section{INTRODUCTION}

The ability of the nervous system to react to hypoxic/ischemic conditions is important for the cellular survival. Most studies have focused on the effects of hypoxia/ische- mia on central neurons, with perhaps less attention given to astrocytes or other non-neuronal cell types, in the central nervous system. Astrocytes play relevant functions in brain homeostasis, and recent evidence indicates that they also respond to synaptic activity and influence neuronal activity and synaptic transmission (Araque et al., 2001; Carmignoto, 2000; Haydon, 2001) through the release of gliotransmitters, i.e., intercellular signaling molecules released by glial cells, (for a comprehensive definition of gliotransmitter, see Volterra and Meldolesi, 2005). Adenosine is a powerful modulator of neuronal function (Pascual et al., 2005). During cerebral hypoxia/ischemia, its extracellular concentration increases, which exerts neuroprotective effects via activation of $\mathrm{A} 1$ adenosine receptors inhibiting glutamate release from presynaptic terminals and neuronal activity (Dale et al., 2000; Fowler, 1989; Scammell et al., 2003; Sweeney, 1997). Previous studies have reported that during ischemic-like conditions, cultured astrocytes first release adenine nucleotides, which are subsequently hydrolyzed to adenosine extracellularly, whereas cultured neurons release adenosine following its intracellular formation (Parkinson et al., 2002, 2005; Parkinson and Xiong, 2004). However, the cellular origin of the adenosine released during hypoxia remains unclear. Since astrocytes can release neuroactive substances that modulate synaptic activity, we have investigated whether astrocytes might be responsible for the modulation of the excitatory synaptic transmission under hypoxic conditions through the release of adenosine.

Our data indicate that adenosine must be recognized as a novel gliotransmitter directly released from astrocytes under pathological conditions. Furthermore, present results identify astrocytes as an important cellular element responsible for hypoxia-mediated effects, showing that astrocytes contribute to regulate excitatory synaptic trans-

\footnotetext{
Grant sponsor: Ministerio de Educación y Ciencia; Grant number: BFU2004 00448; Grant sponsor: Comunidad de Madrid; Grant number: SAL/0877/2004 Grant sponsor: Ministerio de Sanidad y Consumo; Grant number: PI041226; Grant sponsors: UCLM-CCM, Fundación "La Caixa", NINDS, NIMH.

*Correspondence to: Valentín Ceña, Unidad Asociada Neurodeath, UCLM-CSIC, Departamento de Ciencias Médicas, Universidad de Castilla-La Mancha, Avda. de Almansa s/n, 02006 Albacete, Spain. E-mail: valentin.cena@uclm.es or Alfonso Araque, Instituto Cajal, CSIC, Doctor Arce 37, Madrid 28002, Spain. E-mail: araque@ que, Institut.csic.es

cajal.csic.es 13 June 2006; Revised 21 August 2006; Accepted 23 August 2006

DOI 10.1002/glia.20431

Published online 25 September 2006 in Wiley InterScience (www.interscience. wiley.com).
} 
mission through the release of adenosine in response to hypoxic conditions.

\section{MATERIALS AND METHODS Hippocampal Slice Preparation}

All experiments were performed in accordance with guidelines of the European Union (86/609/EEC) for the use of laboratory animals, and every effort was made to minimize the number of animals used. Full details for most of the procedures have been described previously (Martín and Buño, 2003). Briefly, transverse slices $(400 \mu \mathrm{m})$ of the dorsal hippocampus from Wistar rats (13-17 days old) were cut with a vibratome (Series 1000, TPI, St. Louis) and incubated $\left(\gg 1 \mathrm{~h}\right.$ at $\left.20-22^{\circ} \mathrm{C}\right)$ in gassed $\left(95 \% \mathrm{O}_{2}, 5 \% \mathrm{CO}_{2}\right.$ mixture) artificial cerebrospinal fluid (aCSF). The aCSF contained (in mM): $\mathrm{NaCl} 124, \mathrm{KCl} 2.69, \mathrm{KH}_{2} \mathrm{PO}_{4} 1.25, \mathrm{MgSO}_{4} 2$, $\mathrm{NaHCO}_{3} 26, \mathrm{CaCl}_{2}$, and glucose 10 at $\mathrm{pH}$ 7.4. Slices were transferred to an immersion recording chamber placed in an Axioskop upright-microscope (Carl Zeiss, Göttingen, Germany) equipped with infrared and differential interference contrast imaging devices and with a $40 \times$ water immersion objective, and superfused $(1.5 \mathrm{~mL} / \mathrm{min})$ with gassed aCSF. Transient hypoxic episodes were induced by switching the perfusion from normal aCSF to aCSF containing a $95 \% \mathrm{~N}_{2}, 5 \% \mathrm{CO}_{2}$ mixture, typically for $10 \mathrm{~min}$. Effects of hypoxia and the different drugs used were measured $10 \mathrm{~min}$ after the onset of hypoxia, unless otherwise stated.

\section{Electrophysiology}

Recordings from CA1 hippocampal pyramidal neurons were made using the whole-cell configuration of the patchclamp technique, as previously described (Martín and Buño, 2003). Patch electrodes had a resistance of 4-6 M $\Omega$ when filled with the internal solution that contained (in $\mathrm{mM}$ ): k-gluconate 97.5, $\mathrm{KCl}$ 32.5, EGTA 5, HEPES $10, \mathrm{MgCl}_{2} 1$, and ATP 4 at a $\mathrm{pH}$ of 7.2-7.3, osmolarities between 280 and $290 \mathrm{mOsm} / \mathrm{L}$. Whole-cell recordings in the voltage-clamp modes were obtained with an Axopatch 200A amplifier (Axon Instruments, Foster City, CA). Data was filtered at $2 \mathrm{KHz}$ and transferred to the hard disk of a pentium based computer using a DigiData 1322A interface and the pCLAMP 9.0 software (Axon Instruments). Bipolar Elgiloy electrodes (SSM33A05, WPI, Hertfordshire, UK) were placed in the stratum radiatum near the border of CA1 pyramidal layer to stimulate Schaffer collaterals (SCs). Stimuli were single or paired-pulses $(50-100 \mathrm{~ms}$ delay) delivered at $0.3 \mathrm{~s}^{-1}$ via an S-900 stimulator and S910 isolation unit (Dagan Corporation, MN). Data was compared using the Student's t-test, and values are given as the mean \pm s.e.m.

\section{Transgenic Mice}

In some experiments dn-SNARE mice were used. These mice are characterized by astrocytes-specific expression of the SNARE domain in absence of doxycycline, a tetracycline analog, and result from the cross between two heterozygote lines glial fibrillary acidic protein (GFAP).tTA and tetO.SNARE. Mice were bred until 3 weeks of age in the presence of doxycycline to avoid developmental effects due to the transgene expression and were used for experiments 3 weeks after removal of doxycycline (for further details see Pascual et al., 2005). On hippocampal slices from those mice, extracellular recordings were performed and synaptic transmission was quantified from the slope of the SCevoked field excitatory postsynaptic potentials (fEPSPs) in CA1 area and, the response to hypoxia was compared to wild-type littermate.

\section{Astrocyte Cultures}

Primary cultures of rat cortical astrocytes were prepared according to a modification of the method of McCarthy and deVellis (1980). Briefly, the cerebral hemispheres were aseptically removed from new-born (1-2 days) animals, and cortices were incubated in trypsin for $15 \mathrm{~min}$ at $37^{\circ} \mathrm{C}$. Tissue was then mechanically dissociated and resuspended in Dulbecco's modified Eagle's medium containing $10 \% \mathrm{fe}-$ tal bovine serum and antibiotics. The cells were plated in T175 flasks precoated with poly-l-lysine $(10 \mu \mathrm{g} / \mathrm{mL})$. After 7 days in culture, the flasks were shaken vigorously at $250 \mathrm{rpm}$ for $16 \mathrm{~h}$ to remove neurons, microglia, and oligodendrocytes. Astrocytes were trypsinized and plated into 4well plates. To induce hypoxia, astrocyte cultures were washed once with ACFS, pH 7.4, and 4-well plates were placed into special chambers equipped with thermostat housing. Chambers were incubated at $37^{\circ} \mathrm{C}$ either under hypoxic conditions by gassing the special chamber with a gas mixture consisting of $95 \% \mathrm{~N}_{2}, 5 \% \mathrm{CO}_{2}$, usually for 10 $20 \mathrm{~min}$. For control, the cultures were incubated at $37^{\circ} \mathrm{C}$ under normoxic conditions $\left(95 \% \mathrm{O}_{2}, 5 \% \mathrm{CO}_{2}\right)$ for the same length of time.

\section{Adenosine Measurement}

Adenosine was measured by the chemiluminescent method with a Victor ${ }^{3} 1420$ system (PerkinElmer, Turku, Finland). The assay relies on the determination of hydrogen peroxide formed by sequential catabolism of adenosine, inosine, and hypoxanthine/xanthine to uric acid (Kather et al., 1987). The hydrogen peroxide formed by sequential catabolism of purines to uric acid is detected by the oxidation of luminol in the presence of peroxidase. Determination of adenosine was initiated by addition of $0.1 \mathrm{~mL}$ of bicarbonate buffer containing $25 \mu \mathrm{M}$ luminol, $1.5 \mathrm{U} / \mathrm{mL}$ peroxidase, $2.5 \mathrm{U} / \mathrm{mL}$ adenosine deaminase, $1 \mathrm{U} / \mathrm{mL}$ xanthine oxidase, and $0.3 \mathrm{U} / \mathrm{mL}$ nucleoside phosphorylase. The peak of light emission (usually between 20 and $30 \mathrm{~s}$ ) was taken as a measure of adenosine content. Each batch of peroxidase, xanthine oxidase, and nucleoside phosphorylase was checked for contamination by adenosine deaminase before use. Cultured astrocytes were rinsed with KREBS buffer and incubated at $37^{\circ} \mathrm{C}$ under normoxic or hypoxic condi- 
tions in the same buffer for 10-20 min. In order to quantify adenosine concentration, dose-response relationship between known adenosine concentrations (usually 0.1-5 $\mu \mathrm{M}$ ) and luminescent signal was performed simultaneously in each experimental trial (i.e., normoxia and hypoxia). Protein content in cell lysates was determined in each sample using the Bio-Rad DC protein assay. Adenosine levels were measured in at least three different cultures for each experimental condition and are expressed in nanomoles per milligram of protein.

\section{Immunocytochemistry}

Cells were washed with PBS, fixed for $10 \mathrm{~min}$ in $4 \%$ paraformaldehyde, and blocked for $20 \mathrm{~min}$ with normal goat serum diluted 1:20 in PBS/0.05\% Triton. Then, cells were incubated overnight at $4^{\circ} \mathrm{C}$ with GFAP; (dilution 1:250) antibody (Sigma) and further incubated with antirabbit rhodamine-conjugated secondary antisera (Jackson ImmunoResearch Laboratories, West Grove, PA). The plastic coverslips were mounted on glass slides with Vectashield $\AA$ mounting medium (Vector Laboratories, CA), and cells were observed with an inverted microscope (LEICA DMRXA) equipped with epifluorescence optics and a camera (LEICA dc 500). Immunostaining was abolished by omission of primary antibody. Under our culture conditions, $90 \%$ of the cells were identified as astrocytes using immunofluorescent staining technique for GFAP.

\section{Calcium Imaging in Cultures}

To determine changes in $\left[\mathrm{Ca}^{2+}\right]_{\mathrm{i}}$, astrocytes were incubated with $5 \mu \mathrm{M}$ Fura-2-AM and $0.02 \%$ Pluronic (Molecular Probes, Eugene, OR) for $1 \mathrm{~h}$ in the dark (at room temperature). Following incubation, glass coverslips were placed in the open-bath imaging chamber, and the cells were continuously perfused with aCSF $(1.5 \mathrm{~mL} / \mathrm{min})$. Solutions were made hypoxic by bubbling with $95 \% \mathrm{~N}_{2}, 5 \% \mathrm{O}_{2}$ for at least $10 \mathrm{~min}$ prior to perfusion. Imaging experiments were performed on a Nikon TE-2000-S inverted epifluorescence microscope equipped with a $40 \times$ dipping objective. Cells were excited every $0.3 \mathrm{~s}$ by a SpectraMASTER monochromator (Life Science Resources, Cambridge, UK) at 340 and $380 \mathrm{~nm}$ (total excitation time $0.6 \mathrm{~s}$ ). Fluorescent emission was recorded at $\gg 510 \mathrm{~nm}$ by a C4742-98ER CCD camera (Hamamatsu Photonics, Hamamatsu City, Japan) and images were collected and analyzed with the MetaFluor image processing software. Fura-2 was excited alternately at 340 and $380 \mathrm{~nm}$ and ratios of the resulting images were collected every $5 \mathrm{~s}$. Regions of interest were used to restrict data collection to individual cells.

\section{Calcium Imaging in Slices}

$\mathrm{Ca}^{2+}$ levels in hippocampal astrocytes were monitored by fluorescence microscopy using the $\mathrm{Ca}^{2+}$ indicator calcium green-1-AM. Slices were incubated with calcium
green-1-AM (3-4 $\mu$ l of $7 \mathrm{mM}$ dye were dropped over the hippocampus, attaining a final concentration of $10-14 \mu \mathrm{M}$ of dye and $0.01 \%$ of Pluronic) for $30-60 \mathrm{~min}$ at room temperature. Under these conditions, most of the cells loaded were astrocytes (see e.g., Aguado et al., 2002; Liu et al., 2004; Perea and Araque, 2005). Astrocytes were imaged using a CCD camera (Retiga EX; Qimaging, Canada) attached to an Olympus microscope. Cells were illuminated with a xenon lamp at $490 \mathrm{~nm}$ using a monochromator Polychrome II (T.I.L.L. Photonics, Planegg, Germany) during 200-500 $\mathrm{ms}$, and images acquired every 1-5 s. The monochromator Polychrome II and the CCD camera were controlled and synchronized by the IP Lab software (Scanalytics, Fairfax, VA) that was also used for quantitative epifluorescence measurements. Calcium variations were estimated as changes of the fluorescence signal over baseline $\left(\Delta F / F_{0}\right)$.

\section{Drugs}

Thapsigargin, 8-cyclopentyltheophylline (CPT), Ro 201724, and Suramin were purchased from Tocris Cookson (Bristol, UK). BAPTA-AM was purchased from Molecular Probes (Eugene, OR). Adenosine deaminase was from Roche Applied Science (Mannheim, Germany). All other drugs were purchased from Sigma (St Luis, MO). Drugs were stored as frozen concentrated stock solutions and dissolved in oxygenated aCSF at the desired concentration immediately before use. In most experiments, perfusion of drugs started 10 min after the whole cell configuration was achieved, unless stated otherwise. dl-Fluorocitric acid (FC) was prepared as described previously by Paulsen et al. (1987). Briefly, the barium salt of FC was first dissolved in $0.1 \mathrm{M} \mathrm{HCl}$, and the barium was precipitated from the solution with the addition of $0.1 \mathrm{M} \mathrm{Na}_{2} \mathrm{SO}_{4}$. This solution was then buffered $\left(0.1 \mathrm{M} \mathrm{NaPO}_{4}\right)$ and centrifuged at $800 \mathrm{~g}$ for $10 \mathrm{~min}$. The supernatant containing FC was removed and added to aCSF to a final concentration of $1 \mathrm{mM}$. The slices were incubated in gassed aCSF plus FC for $1 \mathrm{~h}$ and then continuously perfused thereafter during the experiment with the same solution.

\section{RESULTS \\ Activation of Presynaptic Adenosine Receptors Modulates Transmitter Release During Hypoxia}

During hypoxic episodes, the amplitude of excitatory postsynaptic currents (EPSCs) evoked by Schaffer collateral (SC) stimulation decreased progressively, reaching a minimum of $14.3 \pm 0.9 \%(n=7)$ of control amplitude (Fig. 1A; filled circles) $10 \mathrm{~min}$ after the onset of hypoxia. This reduction of evoked EPSCs was fully reversed after washout in oxygenated aCSF. Superfusion with aCSF containing $1 \mu \mathrm{M} \mathrm{CPT}$, a selective $\mathrm{A} 1$ adenosine receptor antagonist, greatly prevented the EPSC reduction induced by the hypoxic episode (EPSC amplitude in the presence of CPT was $75 \pm 4 \%$ from control values; $P<0.001 ; n=7$; Fig. 1A; open circles). To determine whether hypoxia effects on synaptic transmission were exerted pre- or post- 


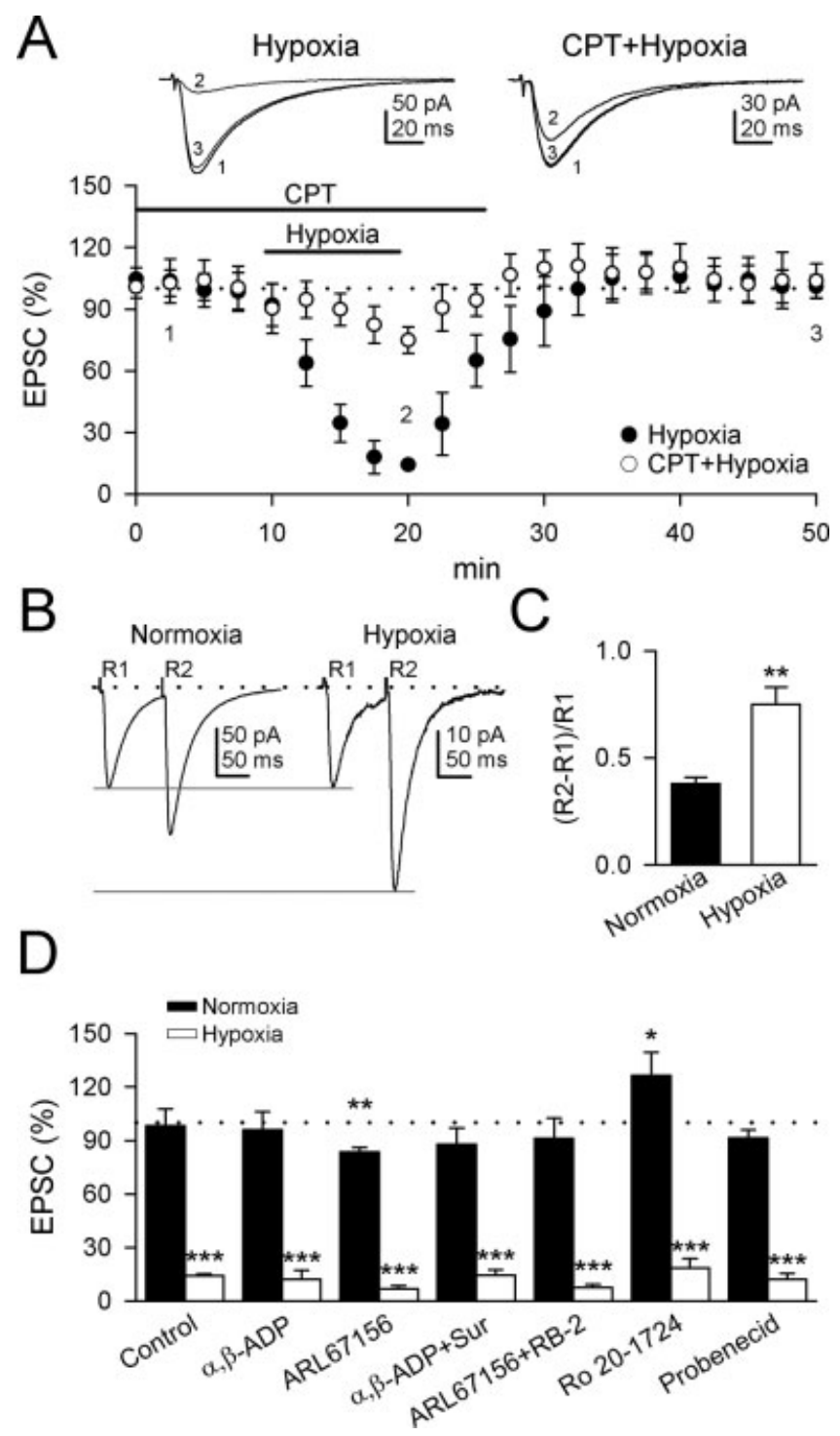

Fig. 1. Hypoxia reduces the EPSC amplitude through an adenosinemediated presynaptic mechanism. A: Time course of hypoxia effects on normalized mean EPSC amplitudes evoked by Schaeffer collateral (SC) stimulation in control (filled circles, $n=7$ ) and in the presence of $1 \mu \mathrm{M}$ CPT (open circles, $n=7$ ). Inset shows averaged EPSCs $(n=20)$, recorded before (1), during (2) and after (3) hypoxia in the absence or presence of CPT. B: Averaged EPSCs $(n=20)$ evoked by paired pulse stimulation (100 ms delay) in normoxia and hypoxia. EPSCs under hypoxia were rescaled so the first EPSC had the same size in normoxic and hypoxic conditions. C: Averaged PPF index [(R2-R1)/R1] was significantly different $(n=6 ; * * P<0.01)$ in normoxia and hypoxia. D: Summary data of hypoxia-induced EPSC reduction in control condition and in the presence of $500 \mu \mathrm{M} \alpha, \beta-\operatorname{ADP}(n=4), 50 \mu \mathrm{M}$ ARL67156 $(n=$ 4), $500 \mu \mathrm{M} \alpha, \beta$-ADP plus $10 \mu \mathrm{M}$ suramin $(n=5), 50 \mu \mathrm{M}$ ARL67156 plus $2 \mu \mathrm{M}$ RB-2 $(n=5), 250 \mu \mathrm{M} \operatorname{Ro} 20-1724(n=6)$ and $1 \mathrm{mM}$ Probenecid $(n=6)$. Significant differences with respect to normoxia were established at $* P<0.05, * * P<0.01$ and $* * * P<0.001$.

synaptically, we estimated changes in the paired pulse facilitation (PPF), which are considered to be of presynaptic origin (Martín and Buño, 2003). The PFF index significantly changed from $0.38 \pm 0.03$ in control to $0.75 \pm 0.08$ in hypoxic conditions $(P<0.01$; Figs. $1 \mathrm{~B}, \mathrm{C} ; n=6)$. The modifications in PPF index that paralleled the hypoxic episode imply that a decreased probability of transmitter release by adenosine is the most likely explanation for the EPSC reduction during hypoxia. Therefore these data confirm that the reduction of evoked EPSCs during hypoxia was selectively mediated by activation of A1 adenosine receptors (Fowler, 1989; Katchman and Hershkowitz, 1993; Zeng et al., 1992) by presynaptic mechanisms (Hershkowitz et al., 1993; Martín et al., 2004; Scammell et al., 2003).

Adenosine can be generated extracellularly through the hydrolysis of released nucleotides by ecto- $5^{\prime}$-nucleotidases (Dunwiddie et al., 1997) or can be produced in the cytosol and transported to the extracellular space (Higgins et al., 1994). We first examined the effects of blocking ecto-5' nucleotidases with $\alpha, \beta$ methylene-ADP ( $\alpha, \beta-\mathrm{ADP})$ (Dunwiddie et al., 1997; Redman and Silinsky, 1994), and the more potent antagonist ARL67156 (Pascual et al., 2005). In normoxic conditions, superfusion of ARL67156 caused a significant reduction of EPSC amplitude $(83.6 \pm 2.5 \%$, $P<0.01$; Fig. 1D; $n=4$ ), that was prevented by the P2 receptor antagonist RB-2, which confirm a previous report demonstrating that ATP accumulation by blockage of ectonucleotidases leads to the inhibition of synaptic transmission (Pascual et al., 2005). In contrast, $\alpha, \beta-\mathrm{ADP}(500 \mu \mathrm{M})$ or ARL67156 $(50 \mu \mathrm{M})$ did not prevent the hypoxia-induced depression of EPSCs [control: $14.3 \pm 0.9 \%$; $\alpha, \beta-\mathrm{ADP}: 12.3$ \pm 5.1.3\%; ARL67156: $6.8 \pm 1.7 \%$; Fig. 1D; $n=4]$. During the ecto-5'-nucleotidase inhibition, a possible enhancement of extracellular ATP, which may inhibit synaptic glutamate release by acting on $\mathrm{P} 2$ receptors in CA1 pyramidal neurons (Mendoza-Fernandez et al., 2000; Pascual et al., 2005), could account for the observed decrease of the EPSC amplitude. We therefore analyzed the effects of $\alpha, \beta-\mathrm{ADP}$ and ARL67156 in the presence of unspecific P2 receptor antagonists that blocks the possible effects of ATP on P2 purinergic receptors. Superfusion with $500 \mu \mathrm{M} \alpha, \beta-\mathrm{ADP}$ plus $10 \mu \mathrm{M}$ suramin did not counteract the EPSC reduction induced by hypoxia (control: $14.3 \pm 0.9 \%$ vs. $\alpha, \beta-\mathrm{ADP}+$ suramin: $14.5 \pm 2.8 \%$; Fig. $1 \mathrm{D} ; n=5$ ). In addition, superfusion with ARL67156 (50 $\mu \mathrm{M})$ plus RB-2 $(2 \mu \mathrm{M})$ failed to prevent the hypoxia-induced depression of synaptic transmission ( $7.7 \pm 1.6 \%$; Fig. $1 \mathrm{D} ; n=5)$. Taken together, these data indicate that extracellular metabolism of adenine nucleotides does not contribute to the adenosine-mediated hypoxic depression of excitatory synaptic transmission in area CA1 of hippocampus.

An alternative potential source of extracellular adenosine is the adenosine- $3^{\prime}, 5^{\prime}$-cyclic adenosine monophosphate (cAMP), which after being released from cells can be subsequently converted to adenosine (Brundege et al., 1997). Because the extracellular conversion of cAMP to adenosine requires first an extracellular phosphodiesterase capable of converting cAMP into adenosine-5'-monophosphate (AMP), we performed experiments with the phosphodiesterase inhibitor Ro 20-1724 (Brundege et al., 1997; Rosenberg et al., 1994), and cAMP transport inhibitor probenecid (Henderson and Strauss, 1991; Rosenberg et al., 1994). In agreement with previous studies (Brundege et al., 1997), Ro20-1724 significantly increased the amplitude of the EPSC (126.3 $\pm 13 \%, P<0.05)$. Neither Ro 20-1724 $(250 \mu \mathrm{M})$ nor probenecid $(1 \mathrm{mM})$ attenuated the effects of 
hypoxia [EPSC reduction was $14.3 \pm 0.9 \%$ in control vs. $18.6 \pm 5.2 \%$ under Ro 20-1724 and $13 \pm 2.7 \%$ under probenecid, Fig. 1D, $n=6$ ]. Taken together, these results indicate that the possible increase of extracellular adenosine levels during hypoxia cannot be accounted for the conversion of cAMP or extracellular ATP catabolism.

\section{Astrocytes Release Adenosine During Hypoxia}

There are several potential cellular sources of endogenous adenosine, including glia (Caciagli et al., 1988), interneurons (Manzoni et al., 1994), and pyramidal cells (Brundege and Dunwiddie, 1996). Recent findings have demonstrated that astrocytes may release different neuroactive substances that can modulate synaptic transmission (for reviews see Araque et al., 2001; Bezzi and Volterra, 2001; Haydon, 2001). We hypothesized that the hypoxic-induced EPSC depression might be mediated by adenosine released from astrocytes. We first investigated the effects of the glia-specific metabolic inhibitor fluorocitrate (FC), (Largo et al., 1996; Paulsen et al., 1987; Swanson and Graham, 1994). Slices were incubated in gassed aCSF plus FC for $1 \mathrm{~h}$ and then continuously perfused thereafter during the experiment with the same solution. We found that $1 \mathrm{mM}$ FC largely prevented the EPSC depression induced by hypoxia from a control value of $14.3 \pm$ $0.9 \%$ to $73 \pm 3 \%$ (Figs. $2 \mathrm{~A}, \mathrm{~B} ; n=6 ; P<0.001$ ). Interestingly, the magnitude of EPSC reduction was similar in the presence of FC or CPT ( $75 \pm 4 \%$; Fig. $2 \mathrm{~B})$. Consistent with this finding, the effects of FC $(1 \mathrm{mM})$ and CPT $(1 \mu \mathrm{M})$ on the hypoxic reduction of EPSC were not additive (EPSC reduction in $\mathrm{FC}+\mathrm{CPT}$ was $64 \pm 12 \%$; Fig. $2 \mathrm{~B} ; n=4$ ) suggesting that both the FC and CPT effects relied on a similar mechanism. Although prolonged treatment with FC has the potential to compromise neuronal and synaptic integrity, we do not feel this is the case because synaptic strength remained relatively constant throughout the 1-h period of whole-cell recording during continuous FC application [mean EPSC amplitude was $82.5 \pm 12.8 \%$ at 60 min after the whole-cell configuration was achieved; Fig. $2 \mathrm{C}$; $n=6]$. Additionally, the EPSC amplitude in FC-treated slices could be reduced by direct application of adenosine, and to a similar extent to control slices (Fig. $2 \mathrm{D} ; n=4$ ), indicating that the neuronal elements and mechanisms involved in the hypoxia-induced adenosine-mediated neuromodulation were preserved after incubation with FC.

The above results suggest that the adenosine responsible for the neuromodulation during hypoxia may be released from the glial cells. To test this idea, we directly examined the extracellular adenosine levels in primary purified astrocyte cultures (Fig. 2E). Using a chemiluminescent method (see Materials and Methods), we found that exposure of astrocyte cultures to hypoxia for 20 min resulted in a marked increase of the extracellular concentration of adenosine present in the medium (Fig. 2F, Control; $P<$ $0.001 ; n=36$ from three different cultures). Since inosine has been shown to be directly released from astrocytes during energy deprivation (Parkinson et al., 2005), control experiments were performed with the adenosine de-
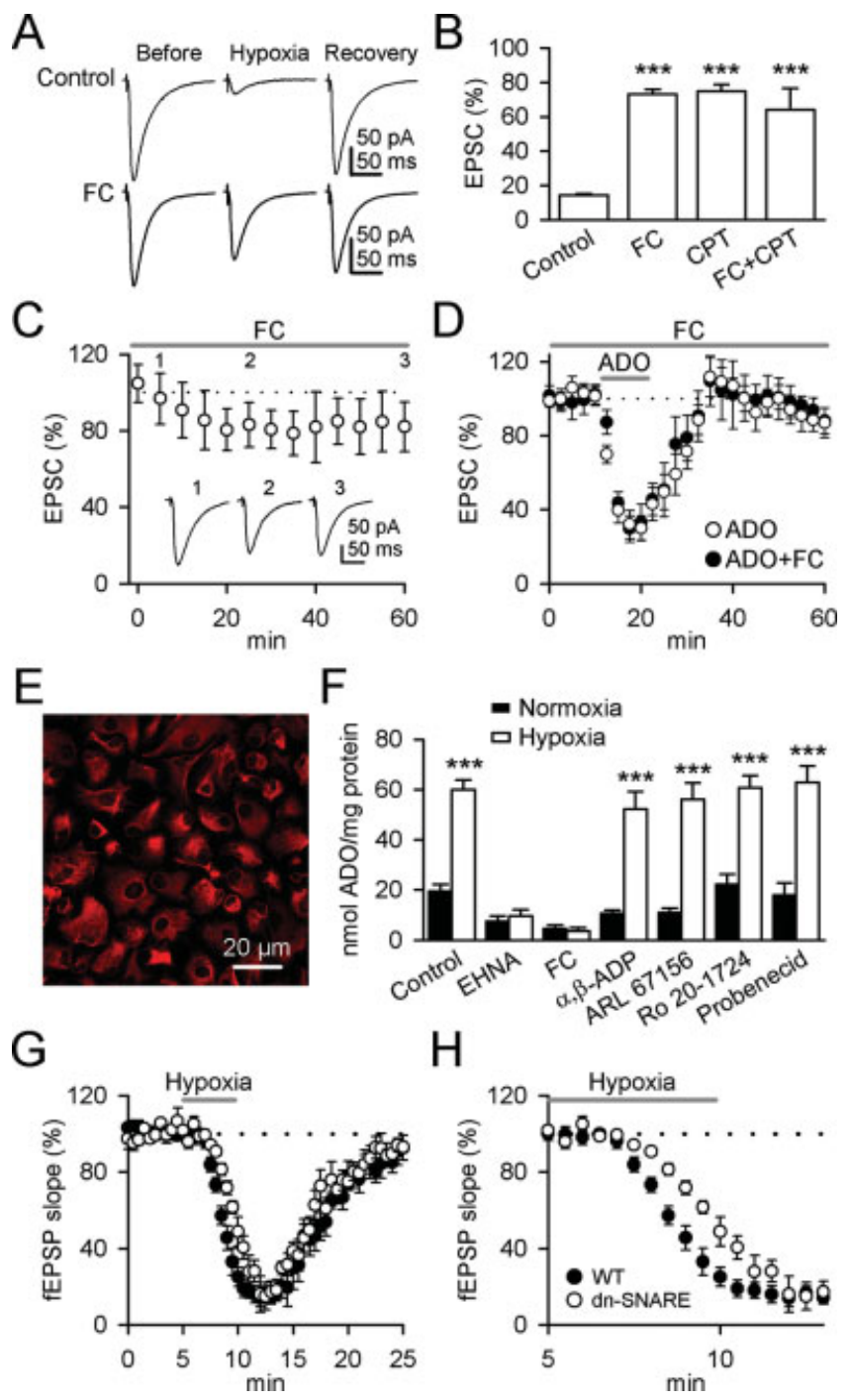

Fig. 2. Hypoxia evokes adenosine release from astrocytes in hippocampal slices and purified astrocyte cultures. A: Averaged EPSCs $(n=$ 20 ) recorded before, during hypoxia (10 $\mathrm{min}$ ), and after recovery, in control condition and after treatments with $1 \mathrm{mM} \mathrm{FC} \mathrm{(see} \mathrm{Materials} \mathrm{and}$ Methods). The holding potential was $-70 \mathrm{mV}$. B: Mean EPSC reduction evoked by 10 min hypoxia in control $(n=7)$, and after treatment with FC $(n=6)$, CPT $(n=7)$ and FC+CPT $(n=4)$. Significant differences from control were established at $* * * P<0.001$. C: Normalized mean EPSC amplitude during perfusion with $1 \mathrm{mM} \mathrm{FC} \mathrm{(} n=4$ slices). Inset shows representative averaged EPSCs $(n=20)$ recorded at the times indicated. D: Effect of $50 \mu \mathrm{M}$ adenosine application on normalized mean EPSC amplitude in control and FC-treated slices (filled and open circles, respectively, $n=4)$. E: Fluorescence image showing purified GFAP-immunoreactive astrocytes in culture. F: Effects of 20 min hypoxia on adenosine release in astrocyte cultures in control conditions $(n=36)$ and after treatment with $1 \mu \mathrm{M}$ EHNA, $1 \mathrm{mM}$ FC, $500 \mu \mathrm{M} \alpha, \beta-\mathrm{ADP}, 50 \mu \mathrm{M}$ ARL67156, $250 \mu \mathrm{M}$ Ro $20-1724$ and $1 \mathrm{mM}$ Probenecid $(n=24$ for each group measured in three different cultures). Significant differences with respect to normoxia were established at $* * * P<0.001$. G: Time course of hypoxia effects on normalized mean fEPSP slope in hippocampal slices from wt (filled circles, $n$ $=5$ ) and dn-SNARE mice (open circle $n=4$ ). H: Expanded time course of same experiment in $\mathrm{G}$ that shown the retardation in the rate of depression of fEPSP. [Color figure can be viewed in the online issue, which is available at www.interscience.wiley.com.]

aminase inhibitor erythro-9-(2-hydroxy-3-nonyl)-adenine (EHNA), which prevents the conversion of adenosine to inosine, to test whether the chemiluminescent assay detected adenosine or inosine release. The luminescent signal 
in either normoxia or hypoxia was practically suppressed in the presence of $1 \mu \mathrm{M}$ EHNA (Fig. $2 \mathrm{~F} ; n=24$ ), indicating that chemiluminescent assay specifically detected adenosine release.

Consistent with findings obtained in slices, the increase of adenosine release during hypoxia was abolished by FC (1 $\mathrm{mM}$ ) but was unaffected by $\alpha, \beta-\mathrm{ADP} \quad(500 \mu \mathrm{M})$, ARL67156 $(50 \mu \mathrm{M})$, Ro 20-1724 $(250 \mu \mathrm{M})$, or probenecid ( $1 \mathrm{mM}$ ) (Fig. $2 \mathrm{~F} ; n=24$ for each group), again supporting the concept that adenosine is directly released by astrocytes during hypoxia and does not result from extracellular metabolism. Interestingly, astrocytes treated with $\alpha, \beta$ $\operatorname{ADP}(500 \mu \mathrm{M})$ or ARL67156 $(50 \mu \mathrm{M})$ showed a significant reduction of the luminescent signal in normoxic conditions (normoxia control: $19.5 \pm 2.7 \mathrm{nmol} / \mathrm{mg}$ protein vs. $\alpha, \beta-$ ADP: $10.5 \pm 1.3 \mathrm{nmol} / \mathrm{mg}$ protein, $P<0.01$ or ARL67156: $10.9 \pm 1.7 \mathrm{nmol} / \mathrm{mg}$ protein, $P<0.01$; Fig. $2 \mathrm{~F} ; n=24$ for each group), indicating that astrocytes release ATP in normoxic conditions, which is in close agreement with previous observations reporting a tonic level of extracellular adenosine due to ATP release (Parkinson et al., 2005; Pascual et al., 2005).

To further test the hypotheses that adenosine release during hypoxia does not result from extracellular ATP catabolism, we investigated the hypoxia effects on synaptic transmission using inducible astrocyte-specific transgenic mice (called dominant-negative SNARE, dn-SNARE mice) in which the SNARE-protein dependent release of ATP is selectively impaired in astrocytes (Pascual et al., 2005). The adenosine-mediated modulation of synaptic transmission during hypoxia was still present in hippocampal slices from dn-SNARE mice and to a similar extent to wild type littermates (Fig. 2G). While the amplitude was similar in wild type and dn-SNARE mice, the onset of the hypoxiainduced EPSC reduction was slightly delayed in the transgenic mice (Fig. 2H), suggesting that the hydrolysis of released ATP plays a small early role in the synaptic suppression but also demonstrating that the major source of adenosine during hypoxia is through direct release from the astrocyte.

Taken together, these observations show that astrocytes directly release the transmitter adenosine in response to hypoxic conditions.

\section{Hypoxia-Induced Adenosine Release from Astrocytes is Negatively Modulated by Calcium Ions}

Astrocytes may release different transmitters that modulate synaptic transmission, and some of these transmitters have been shown to be released in a $\mathrm{Ca}^{2+}$-dependent manner (see Araque et al., 1998, 2000; Liu et al., 2004). Consequently, we first investigated whether the astrocyte $\mathrm{Ca}^{2+}$ signal was regulated by hypoxia in acute hippocampal slices. The astrocyte $\mathrm{Ca}^{2+}$ signal was quantified from the mean resting fluorescence of calcium-green-1 AM-filled astrocytes, the number of astrocytes that displayed spontaneous $\mathrm{Ca}^{2+}$ oscillations (see e.g., Aguado et al., 2002; Latour et al., 2001; Perea and Araque, 2005), and the fre- quency of these oscillations. While hypoxia stimulated a reduction in EPSC amplitude, $\mathrm{Ca}^{2+}$ signaling in astrocytes was not significantly different under normoxic and hypoxic conditions (Fig. 3A).

We next examined whether $\mathrm{Ca}^{2+}$ was involved in the adenosine release during hypoxia in cultured astrocytes. Consistent with the results obtained in slices, the intracellular $\mathrm{Ca}^{2+}$ concentration of cultured astrocytes was not significantly affected by exposure of astrocytes to hypoxia (Figs. 3B,C; $n=63$ ). To examine cellular viability during the hypoxic episodes, we applied $1 \mu \mathrm{M}$ bradykinin that caused a rapid, transient rise of $\left[\mathrm{Ca}^{2+}\right]_{\mathrm{i}}$ (Figs. 3B,C) by releasing $\mathrm{Ca}^{2+}$ from intracellular stores (Smith et al., 2003). Taken together, these results indicate that intracellular $\mathrm{Ca}^{2+}$ signaling in astrocytes was not necessary to evoke hypoxia-induced adenosine release. Likewise, in $\mathrm{Ca}^{2+}$-free solutions (containing $1 \mathrm{mM}$ EGTA) or after voltage-gated $\mathrm{Ca}^{2+}$ channel block by extracellular $\mathrm{Cd}^{2+}$, no significant reduction in hypoxia-induced adenosine release was observed under hypoxia (Fig. 3D; $n=24$ for each group), indicating that the release of adenosine during hypoxia must take place via non-exocytotic mechanisms. We then asked if the adenosine release from astrocytes was affected after depletion of intracellular stores by the $\mathrm{Ca}^{2+}$. ATPase inhibitor thapsigargin ( $1 \mu \mathrm{M}, 30 \mathrm{~min}$ incubation) or after treatment with the intracellular calcium chelator BAPTA-AM (30 $\mu \mathrm{M}$, 30 min incubation). In parallel experiments, we monitored the bradykinin-evoked $\mathrm{Ca}^{2+}$ elevations under the same experimental conditions to confirm the effectiveness of thapsigargin and BAPTA-AM. While either thapsigargin or BAPTA-AM largely prevented $\mathrm{Ca}^{2+}$ elevations (Fig. 3E, upper and middle trace), they did not abolish the increase of adenosine release during hypoxia (Fig. 3D; $n=24$ for each group). Interestingly, chelation of intracellular $\mathrm{Ca}^{2+}$ by BAPTA-AM potentiated the hypoxiainduced adenosine release, which suggests a negative modulation of adenosine release by internal calcium. In addition, we increased the intracellular calcium levels with the calcium ionophore ionomycin $(5 \mu \mathrm{M})$, which reliably increased $\left[\mathrm{Ca}^{2+}\right]_{\mathrm{i}}$ (Fig. 3E, lower trace). Interestingly, ionomycin did not increase the extracellular adenosine levels in control conditions but prevented the adenosine release during hypoxia (Fig. 3D; $n=24$ ). Likewise, increasing the extracellular $\mathrm{Ca}^{2+}$ to $8 \mathrm{mM}$ did not increase the extracellular adenosine concentration in control conditions and abolished the increase of adenosine release during hypoxia (Fig. 3D; $n=24$ ). The absence of hypoxia-induced adenosine release in the presence of ionomycin or high extracellular calcium also indicates that adenosine release is negatively modulated by external or internal $\mathrm{Ca}^{2+}$ concentrations.

Astrocytes are extensively coupled via gap junctions and express a high amount of connexins that can form hemichannels (Giaume and Venance, 1998), which have been proposed to mediate gliotransmitter release. We therefore studied the effects of the gap junction blockers

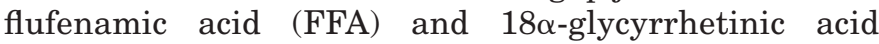

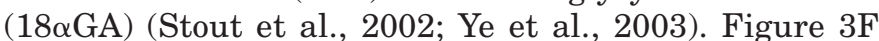
shows that no significant reduction in hypoxia-induced adenosine release was observed in astrocyte cultures 

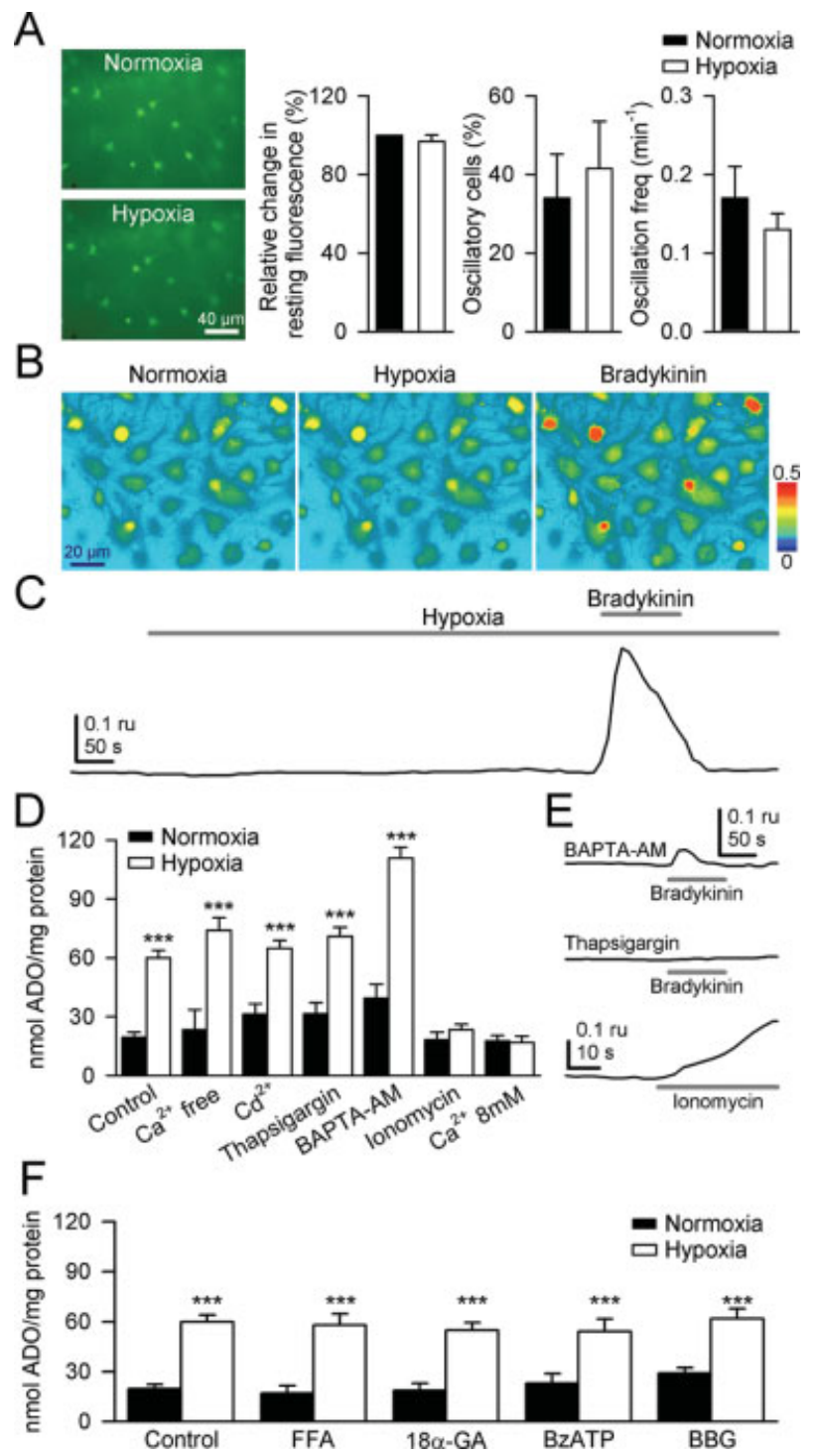

Fig. 3. Hypoxia-induced adenosine release from astrocytes is negatively modulated by calcium ions. A: Left, pseudocolor images representing fluorescence intensities of calcium green-1 loaded hippocampal astrocytes in normoxia and after $10 \mathrm{~min}$ of hypoxia. Right, relative change in astrocytes resting fluorescence after hypoxia $(n=65$ cells from eight slices), relative number of astrocytes that displayed spontaneous $\mathrm{Ca}^{2+}$ oscillations and astrocytic oscillation frequency $(n=31$ astrocytes from seven slices) in normoxic and hypoxic conditions. B: Pseudocolor images of FURA-2-loaded astrocyte cultures in normoxic and hypoxic conditions and after $1 \mu \mathrm{M}$ bradykinin application. C: Temporal plot of $\left[\mathrm{Ca}^{2+}\right]_{\mathrm{i}}$ changes recorded during hypoxia and after bradykinin application in a representative astrocyte. D: Effects of hypoxia $(20 \mathrm{~min})$ on extracellular adenosine concentration in astrocyte cultures in control and after treatment with $\mathrm{Ca}^{2+}$-free (containing $1 \mathrm{mM}$ EGTA), $\mathrm{Cd}^{2+}(100 \mu \mathrm{M})$, thapsigargin $(1 \mu \mathrm{M})$, BAPTA-AM $(30 \mu \mathrm{M})$, Ionomycin $(5 \mu \mathrm{M})$, and $8 \mathrm{mM} \mathrm{Ca}^{2+}(n=$ 24 for each group measured in three different cultures). Differences with respect to normoxia were established at $* * * P<0.001$. E: Temporal plot of $\left[\mathrm{Ca}^{2+}\right]_{\mathrm{i}}$ changes recorded in a representative astrocyte showing the effectiveness of BAPTA-AM (upper trace) and Thapsigargin (middle trace) to prevent bradykinin-evoked calcium elevations, and the ability of ionomycin (lower trace) to increase $\left[\mathrm{Ca}^{2+}\right]_{\mathrm{i}}$. F: Effects of hypoxia $(20 \mathrm{~min})$ on extracellular adenosine levels in astrocytic cultures in control after treatment with $100 \mu \mathrm{M}$ FFA, $50 \mu \mathrm{M} 18 \alpha$-glycyrrhetinic acid (18 $\alpha \mathrm{GA}), 300 \mu \mathrm{M}$ $2^{\prime}-3^{\prime}$-O-(4-Benzoylbenzoyl)-ATP (BzATP) and $50 \mathrm{nM} \mathrm{BBG} \mathrm{(} n=24$ for each group measured in three different cultures). Significant differences with respect to normoxia were established at $* * * P<0.001$. [Color figure can be viewed in the online issue, which is available at www.interscience. wiley.com.] incubated for 10 min with either $100 \mu \mathrm{M}$ FFA or $50 \mu \mathrm{M}$ $18 \alpha \operatorname{GA}(n=24$ for each group).

Previous reports in murine cortical astrocyte cultures show that pore-forming $\mathrm{P}_{2} \mathrm{X}_{7}$ receptors may provide a route for excitatory amino acid release from astrocytes (Duan et al., 2003) because under some conditions these channels may be permeable to molecules up to $900 \mathrm{Da}$ in size (North, 2002). Our results in astrocyte cultures (Fig. 3D) and previous reports in slices (Dale et al., 2000) indicate that adenosine release is reduced by an increase in extracellular $\mathrm{Ca}^{2+}$ concentration. Since an increase in $\mathrm{Ca}^{2+}(>3 \mathrm{mM})$ inhibits ATP-evoked currents at the rat channel-forming $\mathrm{P} 2 \mathrm{X}_{7}$ receptors (North, 2002) and since $\mathrm{P}_{7}$ receptors have been localized in astrocytes (Kukley et al., 2001; Panenka et al., 2001), we next investigate the possibility that $\mathrm{P}_{7}$ receptors might contribute to adenosine release from astrocytes by using the agonist $2^{\prime}-3^{\prime}-o-(4-$ benzoylbenzoyl)-ATP (BzATP) and the antagonist brilliant blue G (BBG). Neither BzATP $(300 \mu \mathrm{M})$ nor BBG $(50 \mathrm{nM})$ modified the extracellular adenosine levels in control or during hypoxia (Fig. $3 \mathrm{~F} ; n=24$ for each group), indicating that channel-forming $\mathrm{P}_{2} \mathrm{X}_{7}$ receptors did not mediate hypoxia-induced adenosine release from astrocytes.

Extracellular levels of adenosine are controlled by nucleoside transporters that can transport adenosine across the cellular membrane. Equilibrative nucleoside transporters (ENTs) passively transport adenosine across cell membranes in either directions depending on the intra and extracellular adenosine concentration through facilitated diffusion (Noji et al., 2004). These transporters are largely responsible for adenosine uptake from the extracellular space in control conditions, but have been proposed to mediate adenosine release from neurons and astrocytes (Bender and Hertz, 1986; Brundege and Dunwiddie, 1996). We investigated the effect of blocking adenosine uptake with the uptake inhibitors dipyridamole (DPM) and $S$-(4-nitrobenzyl)-6-thioinosine (NBTI) (Dunwiddie and Diao, 2000). In hippocampal slices DPM $(10 \mu \mathrm{M})$ plus NBTI $(5 \mu \mathrm{M})$ reduced the basal synaptic transmission, an effect that was counteracted by the A1 adenosine receptor antagonist CPT (Fig. 4A; $n=4$ ), which agrees with previous findings indicating the existence of a tonic level of extracellular adenosine that steadily depresses neurotransmission (Dunwiddie and Diao, 1994; Pascual et al., 2005; Pearson et al., 2001). Moreover, pretreatment with the gliotoxin FC prevented the synaptic depression observed in the presence of antagonists of ENTs further supporting the involvement of glial cells in the control of extracellular adenosine levels (Fig. 4B; $n=4)$. We then investigated the effects of hypoxia after the blockade of ENTs. Adenosine release from cultured astrocytes under hypoxic conditions was not significantly affected by the presence of uptake inhibitors (Fig. 4C; $n=$ 24 for each group). Consistent with these in vitro results, the degree of hypoxia-induced EPSC depression in hippocampal slices was not significantly different in control condition nor in the presence of DPM+NBTI (control: $14.3 \pm 0.9 \%$ vs. DPM+NBTI: $10.1 \pm 1.9 \% ; n=6$ slices; Fig. 4D), in close agreement with previous observations (Pearson et al., 2001). Taken together, these results indi- 
A
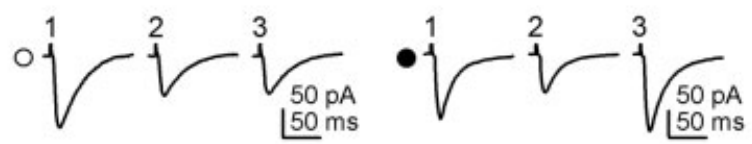

NBTI+DPM

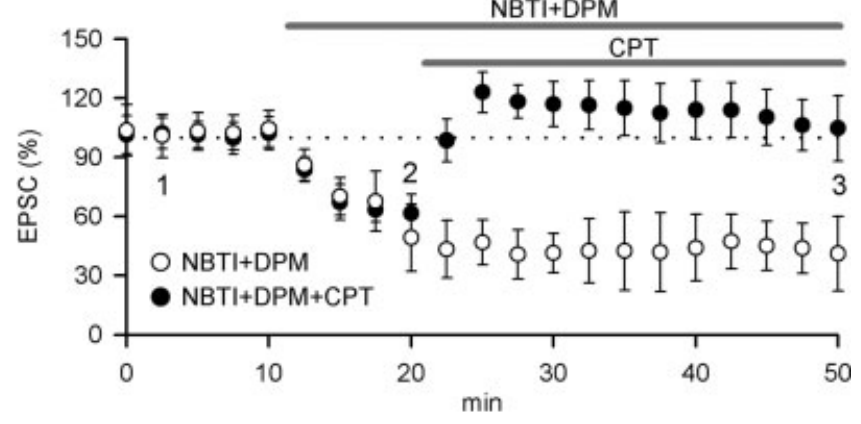

B
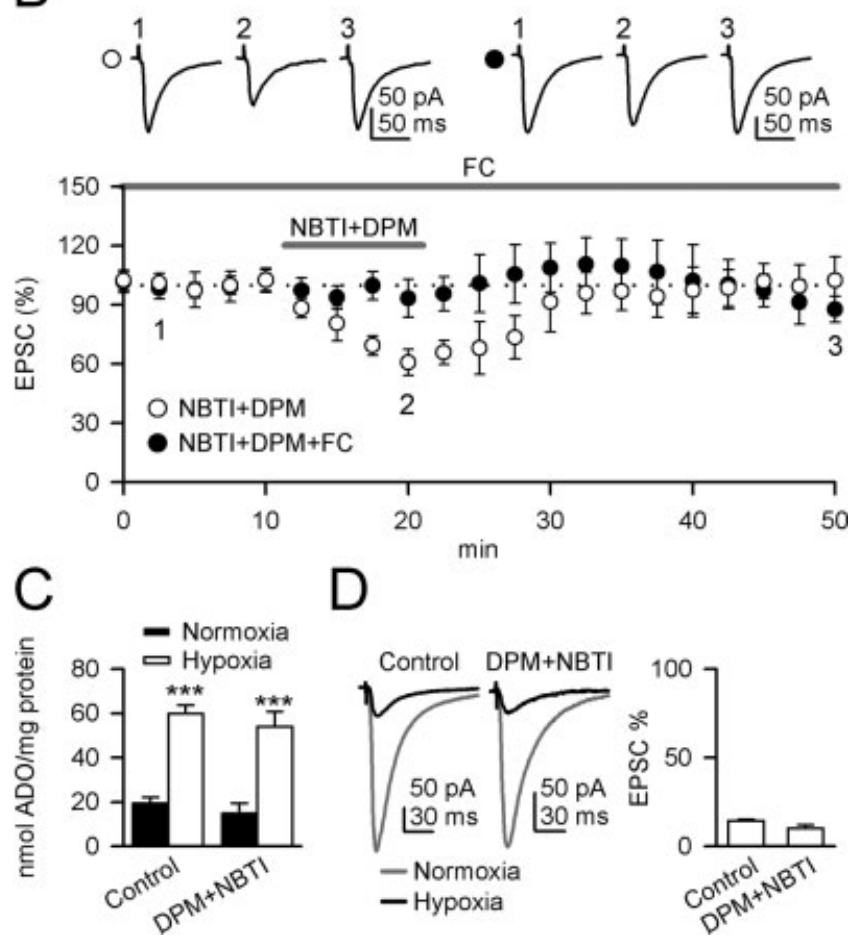

D
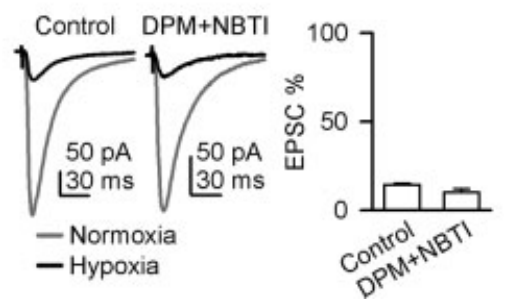

Fig. 4. Effects of adenosine uptake inhibitors on synaptic transmission and hypoxia-induced adenosine release. A: Perfusion with the adenosine transport inhibitors DPM; $(10 \mu \mathrm{M})$ and NBTI; $(5 \mu \mathrm{M})$ depressed EPSC amplitude (open circles; $n=4$ ), and effect that was reverted by application of CPT ( $1 \mu \mathrm{M}$; filled circles; $n=4)$. Traces show representative averaged EPSCs $(n=20)$ recorded at the times indicated. B: Effect of $10 \mu \mathrm{M}$ DPM plus $5 \mu \mathrm{M}$ NBTI on EPSC amplitude in control and FC-treated slices (open and filled circles, respectively, $n=4$ ). Traces show EPSCs $(n=20)$ recorded before (1), during (2) and after (3) DPM plus NBTI application. C: Effects of hypoxia $(20 \mathrm{~min})$ on extracellular adenosine levels in astrocytic cultures in control and after treatment with $10 \mu \mathrm{M}$ DPM plus $5 \mu \mathrm{M}$ NBTI. D: Left, representative traces of averaged EPSCs $(n=20)$ obtained after 10 min of hypoxia in control and during DPM plus NBTI perfusion. Right, mean relative EPSC amplitude reduction after 10 min hypoxia in control $(n=7)$ and during DPM plus NBTI perfusion $(n=6)$.

cate that the increase of extracellular levels of adenosine that underlies the hypoxia effects on hippocampal synaptic transmission were not mediated by changes on the reuptake system.

\section{DISCUSSION}

We have investigated the role of astrocytes in the adenosine-mediated modulation of excitatory synaptic transmission that occurs during hypoxia. Present data demonstrate that this neuromodulation is mediated by adenosine directly released from astrocytes rather than produced by extracellular metabolism of nucleotides that reduces the synaptic transmitter release probability by acting on presynaptic A1 adenosine receptors. Therefore, present results provide experimental demonstration showing that adenosine is a novel gliotransmitter directly released from astrocytes, and that astrocytes play a key neuroprotective role being responsible for the hypoxia-induced modulation of excitatory synaptic transmission in hippocampal slices.

Astrocytes may release different transmitter substances that modulate neuronal excitability and synaptic transmission. These transmitters are called gliotransmitters when released by glial cells (Bezzi and Volterra, 2001). Recently, Volterra and Meldolesi (2005) have proposed the following criteria to be met by a gliotransmitter: first, synthesis by and/or storage in glial cells; second, regulated release triggered by physiological stimuli; third, activation of rapid (milliseconds to seconds) responses in neighboring cells; and fourth, a role in physiological processes. We propose an extension of these criteria to include regulated release by pathological stimuli.

During a variety of insults to the brain, extracellular levels of adenosine largely increase exerting a neuroprotective influence through activation of presynaptic A1 adenosine receptors that inhibit glutamate release (Sweeney, 1997). While the importance of adenosine in the presynaptic depression of hippocampal excitatory transmission during hypoxia is firmly established (Fowler, 1989; Katchman and Hershkowitz, 1993; Zeng et al., 1992), the cellular and biochemical origin of this transmitter was unknown. Both astrocytes and neurons can be the cellular source of extracellular adenosine, which can be produced in the cytosol and transported to the extracellular space (Higgins et al., 1994) or generated extracellularly through the hydrolysis of released nucleotides by ecto-5'-nucleotidases (Dunwiddie et al., 1997). Our results show that hypoxia effects are prevented by the specific gliotoxin $\mathrm{FC}$, which closely mimics the effects of $\mathrm{A} 1$ adenosine receptor antagonist CPT, and that the extracellular levels of adenosine in purified astrocytic cultures increase during hypoxia, indicating that astrocytes are the main cellular source of adenosine produced during hypoxia. On the other hand, in agreement with previous reports (Pearson et al., 2003), several lines of evidence suggest that the increase of adenosine levels during hypoxia does not result from the extracellular ATP or cAMP metabolism. Indeed, inhibition of ecto-5' ${ }^{\prime}$-nucleotidases, phosphodiesterase, and cAMP transport did not modify the synaptic transmission depression during hypoxia (Pearson et al., 2003) or adenosine concentration in astrocyte cultures. Finally, though slightly delayed, the presence of adenosine-mediated modulation of hippocampal synaptic transmission during hypoxia in transgenic mice with impaired ATP release (astrocyte selective dn-SNARE mice) strongly indicates that the majority of the adenosine med- 
iating the hypoxic effects is not produced by extracellular ATP degradation, rather it is released from the cytosol.

Previous studies have shown that under normoxic conditions the extracellular adenosine was mainly derived from the extracellular catabolism of ATP (Brundege et al., 1997; Dunwiddie et al., 1997; Pascual et al., 2005). In agreement with those results, a significant reduction of the extracellular levels of adenosine was observed in normoxic conditions in the presence of ecto-5'-nucleotidase blockers. Present results indicate, however, a direct release of adenosine during hypoxia, which contrasts but does not contradict the results describing ATP release under physiological conditions. Therefore, present data obtained under non physiological conditions suggest that the mechanisms underlying purine release under hypoxia may differ from those involved in physiological normal conditions.

Both neurons and astrocytes have been proposed to release adenosine under ischemic-like conditions (Parkinson et al., 2002, 2005; Parkinson and Xiong, 2004). In those studies, astrocytes were shown to release adenine nucleotides, which were converted to adenosine in the extracellular space by ecto-5'-nucleotidases, rather than to release adenosine directly as the current study shows. However, this apparent discrepancy may be accounted for the different experimental conditions tested. Indeed, while those studies used oxygenglucose deprivation (i.e. ischemic-like conditions), we here studied the effects of oxygen deprivation (i.e. hypoxic conditions). Moreover, they showed a significant increase in adenosine release from neurons and astrocytes only after $60 \mathrm{~min}$ of oxygen-glucose deprivation onset (Parkinson and Xiong, 2004), while our results were evoked by a transient hypoxia (10-20 min). Therefore, it is likely that ischemic or hypoxic conditions as well as their duration trigger different mechanisms of purine release.

The molecular mechanism by which adenosine is released into the extracellular space during hypoxia is still unclear. Adenosine release and uptake from glia and pyramidal cells under certain conditions is mediated by facilitated transport (Brundege and Dunwiddie, 1996; Caciagli et al., 1988); therefore a way to raise the extracellular level of adenosine during hypoxia is to block adenosine uptake. In the present work, we found that the combination of adenosine uptake inhibitors DPM+NBTI failed to prevent the hypoxia-induced adenosine release in both hippocampal slices and astrocyte cultures. However, when considering the properties of nucleoside equilibrative transporters, these results do not necessarily rule out the involvement of these transporters.

The dependence of calcium on adenosine production and release during hypoxia is a key issue. Experiments performed in $\mathrm{Ca}^{2+}$-free conditions or after blockade of voltagegated $\mathrm{Ca}^{2+}$ channels by extracellular $\mathrm{Cd}^{2+}$ show that the release of adenosine during hypoxia must take place via non-exocytotic mechanisms. These observations are in agreement with previous studies in hippocampal slices (Dale et al., 2000). This idea is further supported by the fact that adenosine release still occurs in transgenic mice in which the SNARE-dependent release of gliotransmitters was impaired. Interestingly, chelation of intracellular $\mathrm{Ca}^{2+}$ by BAPTA-AM increases hypoxia-induced adenosine release, while enhancement of intracellular $\mathrm{Ca}^{2+}$ by ionomy- cin reduced adenosine concentration found in the culture medium. Furthermore, increasing extracellular $\mathrm{Ca}^{2+}$ to 8 $\mathrm{mM}$ in astrocyte cultures prevented the increase of adenosine release during hypoxia. Taken together, these findings indicate that the processes involved in the production and/ or release of adenosine are negatively modulated by external or internal $\mathrm{Ca}^{2+}$ concentrations. Some element involved in the production or release of adenosine seems to be $\mathrm{Ca}^{2+}$ sensitive, e.g. enzymes involved in the production of adenosine. Nevertheless, further studies are required to determine the mechanism underlying adenosine release and to establish the role and function of intracellular $\mathrm{Ca}^{2+}$ signal in this mechanism.

In conclusion, here we show that astrocytes respond to the hypoxia releasing adenosine that presynaptically modulates the excitatory synaptic transmission in hippocampal slices. Present results provide the first experimental demonstration that identifies astrocytes as a key cellular element responsible for hypoxia-mediated regulation of synaptic transmission. Therefore, astrocytes must be considered as a cellular target to develop future therapeutical approaches to cerebrovascular dysfunction.

\section{REFERENCES}

Aguado F, Espinosa-Parrilla JF, Carmona MA, Soriano E. 2002. Neuronal activity regulates correlated network properties of spontaneous calcium transients in astrocytes in situ. J Neurosci 22:9430-9444.

Araque A, Carmignoto G, Haydon PG. 2001. Dynamic signaling between neurons and glia. Annu Rev Physiol 63:795-813.

Araque A, Li N, Doyle RT, Haydon PG. 2000. SNARE protein dependent glutamate release from astrocytes. J Neurosci 20:666-673.

Araque A, Sanzgiri RP, Parpura V, Haydon PG. 1998. Calcium elevation in astrocytes causes an NMDA receptor-dependent increase in the frequency of miniature synaptic currents in cultured hippocampal neurons. J Neurosci 18:6822-6829.

Bender AS, Hertz L. 1986. Similarities of adenosine uptake systems in astrocytes and neurons in primary cultures. Neurochem Res 11:15071524 .

Bezzi P, Volterra A. 2001. A neuron-glia signalling network in the active brain. Curr Opin Neurobiol 11:387-394.

Brundege JM, Diao L, Proctor WR, Dunwiddie TV. 1997. The role of cyclic AMP as a precursor of extracellular adenosine in the rat hippocampus. Neuropharmacology 36:1201-1210.

Brundege JM, Dunwiddie TV. 1996. Modulation of excitatory synaptic transmission by adenosine released from single hippocampal pyramidal neurons. J Neurosci 16:5603-5612.

Caciagli F, Ciccarelli R, Di Iorio P, Ballerini P, Tacconelli L. 1988. Cultures of glial cells release purines under field electrical stimulation: The possible ionic mechanisms. Pharmacol Res Commun 20:935-947.

Carmignoto G 2000. Reciprocal communication systems between astrocytes and neurons. Prog Neurobiol 62:561-581.

Dale N, Pearson T, Frenguelli BG. 2000. Direct measurement of adenosine release during hypoxia in the CA1 region of the rat hippocampal slice. J Physiol 526:143-155.

Duan S, Anderson CM, Keung EC, Chen Y, Chen Y, Swanson RA. 2003. P2X7 receptor-mediated release of excitatory amino acids from astrocytes. J Neurosci 23:1320-1328.

Dunwiddie TV, Diao L. 1994. Extracellular adenosine concentration in hippocampal brain slices and the tonic inhibitory modulation of evoked excitatory responses. J Pharmacol Exp Ther 268:537-545.

Dunwiddie TV, Diao L. 2000. Regulation of extracellular adenosine in rat hippocampal slices is temperature dependent: Role of adenosine transporters. Neuroscience 95:81-88.

Dunwiddie TV, Diao L, Proctor WR. 1997. Adenine nucleotides undergo rapid, quantitative conversion to adenosine in the extracellular space in rat hippocampus. J Neurosci 17:7673-7682.

Fowler JC 1989. Adenosine antagonists delay hypoxia-induced depression of neuronal activity in hippocampal brain slice. Brain Res 490: 378-384. 
Giaume C, Venance L. 1998. Intercellular calcium signalling and gap junctional communication in astrocytes. Glia 24:50-64.

Haydon PG 2001. Glia: Listening and talking to the synapse. Nat Rev Neurosci 2:185-193.

Henderson GB, Strauss BP. 1991. Evidence for cAMP and cholate extrusion in $\mathrm{C} 6$ rat glioma cells by a common anion efflux pump. J Biol Chem 266:1641-1645.

Hershkowitz N, Katchman AN, Veregge S. 1993. Site of synaptic depression during hypoxia: A patch-clamp analysis. J Neurophysiol 69:432-441.

Higgins MJ, Hosseinzadeh H, MacGregor DG, Ogilvy H, Stone TW. 1994. Release and actions of adenosine in the central nervous system. Pharm World Sci 16:62-68.

Katchman AN, Hershkowitz N. 1993. Adenosine antagonists prevent hypoxia-induced depression of excitatory but not inhibitory synaptic currents. Neurosci Lett 159:123-126.

Kather H, Wieland E, Waas W. 1987. Chemiluminescent determination of adenosine, inosine, and hypoxanthine/xanthine. Anal Biochem 163: $45-51$.

Kukley M, Barden JA, Steinhauser C, Jabs R. 2001. Distribution of $\mathrm{P} 2 \mathrm{X}$ receptors on astrocytes in juvenile rat hippocampus. Glia 36:1121.

Largo C, Cuevas P, Somjen GG, Martin del Rio R, Herreras O. 1996. The effect of depressing glial function in rat brain in situ on ion homeostasis, synaptic transmission, and neuron survival. J Neurosci 16: 1219-1229.

Latour I, Gee CE, Robitaille R, Lacaille JC. 2001. Differential mechanisms of $\mathrm{Ca}^{2+}$ responses in glial cells evoked by exogenous and endogenous glutamate in rat hippocampus. Hippocampus 11:132-145.

Liu QS, Xu Q, Arcuino G, Kang J, Nedergaard M. 2004. Astrocytemediated activation of neuronal kainate receptors. Proc Natl Acad Sci USA 101:3172-3177.

Manzoni OJ, Manabe T, Nicoll RA. 1994. Release of adenosine by activation of NMDA receptors in the hippocampus. Science 265:20982101.

Martín ED, Buño W. 2003. Caffeine-mediated presynaptic long-term potentiation in hippocampal CA1 pyramidal neurons. J Neurophysiol 89:3029-3038.

Martín ED, Gonzalez-García C, Milán M, Fariñas I, Ceña V. 2004. Stressor-related impairment of synaptic transmission in hippocampa slices from $\alpha$-synuclein knockout mice. Eur J Neurosci 20:3085-3091.

McCarthy KD, deVellis J. 1980. Preparation of separate astroglial and oligodendroglial cell cultures from rat cerebral tissue. J Cell Biol 85: 890-902.

Mendoza-Fernandez V, Andrew RD, Barajas-Lopez C. 2000. ATP inhibits glutamate synaptic release by acting at P2Y receptors in pyramidal neurons of hippocampal slices. J Pharmacol Exp Ther 293:172179

Noji T, Karasawa A, Kusaka H. 2004. Adenosine uptake inhibitors. Eur J Pharmacol 495:1-16.

North RA 2002. Molecular physiology of P2X receptors. Physiol Rev 82: 1013-1067.

Panenka W, Jijon H, Herx LM, Armstrong JN, Feighan D, Wei T, Yong VW, Ransohoff RM, MacVicar BA. 2001. P2X7-like receptor activation in astrocytes increases chemokine monocyte chemoattractant protein-1 expression via mitogen-activated protein kinase. J Neurosci 21:71357142 .

Parkinson FE, Sinclair CJ, Othman T, Haughey NJ, Geiger JD. 2002 Differences between rat primary cortical neurons and astrocytes in purine release evoked by ischemic conditions. Neuropharmacology 43:836-846.

Parkinson FE, Xiong W. 2004. Stimulus- and cell-type-specific release of purines in cultured rat forebrain astrocytes and neurons. J Neurochem 88:1305-1312.

Parkinson FE, Xiong W, Zamzow CR. 2005. Astrocytes and neurons: Different roles in regulating adenosine levels. Neurol Res 27:153160.

Pascual O, Casper K, Kubera C, Zhang J, Revilla-Sanchez R, Moss S, McCarthy K, Haydon PG. 2005. Astrocytic purinergic signaling coordinates synaptic networks. Science 310:113-116.

Paulsen RE, Contestabile A, Villani L, Fonnum F. 1987. An in vivo model for studying function of brain tissue temporarily devoid of glial cell metabolism: The use of fluorocitrate. J Neurochem 48:1377-1385.

Pearson T, Currie AJ, Etherington LA, Gadalla AE, Damian K, Llaudet E, Dale N, Frenguelli BG. 2003. Plasticity of purine release during cerebral ischemia: Clinical implications? J Cell Mol Med 7:362-375.

Pearson T, Nuritova F, Caldwell D, Dale N, Frenguelli BG. 2001. A depletable pool of adenosine in area CA1 of the rat hippocampus. J Neurosci 21:2298-2307.

Perea G, Araque A. 2005. Properties of synaptically evoked astrocyte calcium signal reveal synaptic information processing by astrocytes. J Neurosci 25:2192-2203.

Redman RS, Silinsky EM. 1994. ATP released together with acetylcholine as the mediator of neuromuscular depression at frog motor nerve endings. J Physiol 477:117-127.

Rosenberg PA, Knowles R, Knowles KP, Li Y. 1994. $\beta$-Adrenergic receptor-mediated regulation of extracellular adenosine in cerebral cortex in culture. J Neurosci 14:2953-2965.

Scammell TE, Arrigoni E, Thompson MA, Ronan PJ, Saper CB, Greene RW. 2003. Focal deletion of the adenosine A1 receptor in adult mice using an adeno-associated viral vector. J Neurosci 23:5762-5770.

Smith IF, Boyle JP, Plant LD, Pearson HA, Peers C. 2003. Hypoxic remodeling of $\mathrm{Ca}^{2+}$ stores in type I cortical astrocytes. J Biol Chem 278 : 4875-4881.

Stout CE, Costantin JL, Nau CC, Charles AC. 2002. Intercellular calcium signalling in astrocytes via ATP release through connexin hemichannels. J Biol Chem 277:10482-10488.

Swanson RA, Graham SH. 1994. Fluorocitrate and fluoroacetate effects on astrocyte metabolism in vitro. Brain Res 664:94-100.

Sweeney MI 1997. Neuroprotective effects of adenosine in cerebral ischemia: Window of opportunity. Neurosci Biobehav Rev 21:207-217.

Volterra A, Meldolesi J. 2005. Astrocytes, from brain glue to communication elements: The revolution continues. Nat Rev Neurosci 6:626640.

Ye ZC, Wyeth MS, Baltan-Tekkok S, Ransom BR. 2003. Functional hemichannels in astrocytes: A novel mechanism of glutamate release. J Neurosci 23:3588-3596.

Zeng YC, Domenici MR, Frank C, Sagratella S, Scotti de Carolis A. 1992. Effects of adenosinergic drugs on hypoxia-induced electrophysiological changes in rat hippocampal slices. Life Sci 51:1073-1082. 